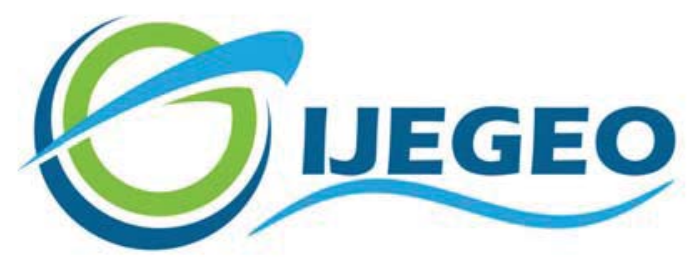

International Journal of Environment and Geoinformatics (IJEGEO) is an international, multidisciplinary, peer reviewed, open access journal.

\title{
Methylene Blue Removal by Activated Carbon from platanus orientalis Leaves
}

\section{Ozan TOPRAKCI, H. Aylin KARAHAN TOPRAKCI, Hikmet OKKAY}

\author{
Chief in Editor \\ Prof. Dr. Cem Gazioğlu \\ Co-Editors \\ Prof. Dr. Dursun Zafer Şeker, Prof. Dr. Şinasi Kaya, \\ Prof. Dr. Ayşegül Tanık and Assist. Prof. Dr. Volkan Demir
}

Editorial Committee (September 2021)

Assoc. Prof. Dr. Abdullah Aksu (TR), Assit. Prof. Dr. Uğur Algancı (TR), Prof. Dr. Bedri Alpar (TR), Assoc. Prof. Dr. Aslı Aslan (US), Prof. Dr. Levent Bat (TR), Prof. Dr. Paul Bates (UK), İrşad Bayırhan (TR), Prof. Dr. Bülent Bayram (TR), Prof. Dr. Luis M. Botana (ES), Prof. Dr. Nuray Çağlar (TR), Prof. Dr. Sukanta Dash (IN), Dr. Soofia T. Elias (UK), Prof. Dr. A. Evren Erginal (TR), Assoc. Prof. Dr. Cüneyt Erenoğlu (TR), Dr. Dieter Fritsch (DE), Prof. Dr. Çiğgem Göksel (TR), Prof.Dr. Lena Halounova (CZ), Prof. Dr. Manik Kalubarme (IN), Dr. Hakan Kaya (TR), Assist. Prof. Dr. Serkan Kükrer (TR), Assoc. Prof. Dr. Maged Marghany (MY), Prof. Dr. Michael Meadows (ZA), Prof. Dr. Nebiye Musaoğlu (TR), Prof. Dr. Masafumi Nakagawa (JP), Prof. Dr. Hasan Özdemir (TR), Prof. Dr. Chryssy Potsiou (GR), Prof. Dr. Erol Sarı (TR), Prof. Dr. Maria Paradiso (IT), Prof. Dr. Petros Patias (GR), Prof. Dr. Elif Sertel (TR), Prof. Dr. Nüket Sivri (TR), Prof. Dr. Füsun Balık Şanlı (TR), Prof. Dr. Uğur Şanlı (TR), Duygu Ülker (TR), Prof. Dr. Seyfettin Taş (TR), Assoc. Prof. Dr. Ömer Suat Taşkın (TR), Assist. Prof. Dr. Tuba Ünsal (TR), Dr. Manousos Valyrakis (UK), Dr. İnese Varna (LV), Dr. Petra Visser (NL), Prof. Dr. Selma Ünlü (TR), Assoc. Prof. Dr. Oral Yağcı (TR), Prof. Dr. Murat Yakar (TR), Assoc. Prof. Dr. İ. Noyan Yılmaz (AU); Assit. Prof. Dr. Sibel Zeki (TR) 


\title{
Methylene Blue Removal by Activated Carbon from platanus orientalis Leaves
}

\author{
Ozan Toprakci $^{1 * *}$ (D) , H. Aylin Karahan Toprakci ${ }^{1}$ iD, Hikmet Okkay $^{2}$ i \\ ${ }^{1}$ Department of Polymer Materials Engineering, Faculty of Engineering, Yalova University, Yalova, Turkey \\ ${ }^{2}$ Department of Chemical Engineering, Faculty of Engineering, Yalova University, Yalova, Turkey \\ * Corresponding author: O. Toprakci \\ * E-mail: ozan.toprakci@yalova.edu.tr
}

How to cite: Toprakci, et al., (2021). Methylene blue removal by activated Carbon from Platanus Orientalis Leaves. International Journal of Environment and Geoinformatics (IJEGEO), 8(3):283-289. doi. 10.30897/ijegeo. 858437

\begin{abstract}
In this study, activated carbon was produced from platanus orientalis leaves and the adsorption of methylene blue onto activated carbon was investigated. Facile chemical activation route was conducted for activation process of lignocellulosic leaves. $\mathrm{ZnCl}_{2}$ was used as an activating agent at different ratios. Morphological, structural properties and adsorption characteristics of samples were determined by using field emission scanning microscopy, Fourier transform infrared spectroscopy, Braunauer-Emmet-Teller spectroscopy and UV-vis spectroscopy. Surface characterization showed that activation with $\mathrm{ZnCl}_{2}$ resulted high surface area ( 1024 $\left.\mathrm{m}^{2} \mathrm{~g}^{-1}\right)$ and total pore volume $\left(\sim 0.431 \mathrm{~cm}^{3} \mathrm{~g}^{-1}\right)$ compared with crude carbonized leaves samples.
\end{abstract}

Keywords: Methylene blue, Platanus Orientalis Leaves, Activated Carbon, Dye Removal

\section{Introduction}

Dyes and pigments are highly used chemicals for several industries such as textiles, leather, paper, etc. Global annual production of dyes and pigments in 2021 is estimated over 10000 ktons (Wong, et al., 2004). Around $10-15 \%$ of dye products are wasted during these industrial processes and this creates huge amount of pollution (Dahiya and Nigam, 2020). Among chemical and biological dyes, methylene blue (MB) is a widely used cationic dye which especially used in cotton or silk dying. Its wastewater suffers from poor biodegradability, high chromaticity and high toxicity which adversely affect health in the water environment (Kuang, et al., 2008). Therefore, removal of MB from effluent is of great importance in order to protect environment. Also, dimensions of $\mathrm{MB}$ molecule are $\sim 13.82-14.47 \AA$ in length and $\sim 9.5 \AA$ in width (Dotto et al., 2015; Macedo et al., 2006). These dimensions are making MB a suitable material for characterization of meso- or microporous surfaces.

Platanus orientalis is one of the common trees in the world from southeast Europe to India and China. When it is mature enough, it can easily be noticed from widely spreading branches and characteristic leaves with multiple lobes. Since it is a large tree and can grow up to $30-40 \mathrm{~m}$ tall, it is cultivated in order to obtain timber esp. for furniture production. It is also a cultural symbol in Iran, Turkey and India (Abadian, et al., 2015; Rinaldi et al., 2019; Sevik, et al., 2019). Even in Turkey there is a district called Cinarcik (means little Platanus orientalis) in Yalova. This name was given because of dominant platanus orientalis forests in the vicinity. Platanus orientalis is a deciduous tree and depending on the maturity of the tree, it sheds thousands of leaves during autumn. Since Platanus orientalis leaves (POL) are highly abundant, sustainable source and free of charge, it can be used for various applications including adsorbents (Abadian et al., 2015; Mahvi, et al., 2007; Peydayesh and RahbarKelishami, 2015; Sert et al., 2008), and bioindicators (Norouzi and Khademi, 2015). Among these, wastewater treatments are the most common application. In these studies, generally leaves were collected, washed, dried and ground. Then they were used as adsorbents for predetermined chemicals. Since they are biological structures, their components have various functional active sides, they can be used as biosorbents for cadmium (Mahvi et al., 2007), copper(II) (Abadian et al., 2015), lanthanum and cerium(III) adsorption (Sert et al., 2008). In addition to these, leaves of platanus orientalis was also used for hydro char fabrication. Gu et al., prepared hydro char from platanus orientalis leaves by combination of persulfate oxidation and hydrothermal treatment. As reported in the study, energy yield increased noticeably (Gu et al., 2017). Active carbon fabrication was reported as another application of POL. Liu et al., fabricated active carbon by a microwave assisted process using $\mathrm{H}_{3} \mathrm{PO}_{4}$ for activation. The surface area of the active carbon was around $1090 \mathrm{~m}^{2} \mathrm{~g}^{-1}$ with the pore volume of $1.468 \mathrm{~cm}^{3}$. $\mathrm{Cr}(\mathrm{VI})$ adsorption was investigated and results well-fitted with pseudosecond-order model (Liu et al., 2018). One recent study about POL based active carbon was carried out by Jiang et al. Microspheres were synthesized by combination of hydrothermal carbonization and calcination. $\mathrm{H}_{2} \mathrm{SO}_{4}$ and $\mathrm{KOH}$ were used as the catalyst and activator, respectively. The specific surface area was reported as $1355.53 \mathrm{~m}^{2} \mathrm{~g}^{-1}$. Samples showed good adsorption behavior for rhodamine $\mathrm{B}$ and methyl 
orange mainly because of hydroxyl and carboxyl groups on the surface (Jiang et al., 2020). Musah et al. fabricated two types of active carbon from POL. First sample was only thermally treated second sample was both thermally treated and treated with $\mathrm{H}_{3} \mathrm{PO}_{4}$. The second sample showed higher performance in terms of methylene blue removal from the solution. However, surface area was not given in the study (Musah, Peng, and $\mathrm{Xu}, 2020)$. As can be seen from the recent literature, the number of the studies about POL based active carbon is very limited. In the studies mentioned above, microwave and hydrothermal synthesis routes were used. For the activation $\mathrm{H}_{3} \mathrm{PO}_{4}, \mathrm{KOH}$ were used as activators. In this study another route and chemicals were used for the preparation of active carbon. $\mathrm{ZnCl}_{2}$ activated carbon from POL was synthesized and used as an adsorbent for MB. Ground POL were impregnated into $\mathrm{ZnCl}_{2}$ /water solutions and dried. Carbonization was carried out $700{ }^{\circ} \mathrm{C}$. In order to increase the surface area, samples were treated with $\mathrm{HCl}$ solution. $\mathrm{ZnCl}_{2}$ mass ratio on yield, morphology, surface texture and adsorption performance were analyzed, and the most optimum ratio was used in determination of kinetic MB adsorption measurements. As far as known, there is no study in the literature that focused on this type of process for POL based active carbon fabrication and characterization.

\section{Materials and Methods Activated Carbon Preparation}

Schematic illustration of experimental procedure used in this study was shown in Fig. 1. Dry leaves of plane tree (platanus orientalis) were collected from Samanli Mountains (Yalova, Turkey) in October 2020. Dry leaves were collected from the trees that were around 20-30 years old. Firstly, raw material was washed with distilled water in order to remove the dirt for 4 times and dried in oven at $100{ }^{\circ} \mathrm{C}$ for $12 \mathrm{~h}$. Dried leaves were ground and sieved by using a stainless-steel sieve (100 mesh $<149 \mu \mathrm{m})$. 1, 2, $3 \mathrm{~g} \mathrm{ZnCl}_{2}$ was dissolved in 100 $\mathrm{ml}$ distilled water and 3 different solutions were prepared. Following that, $5 \mathrm{~g}$ of sieved leaf particles were impregnated into $\mathrm{ZnCl}_{2}$ solutions. As a result of this 3 different mixtures were obtained with the leaf to activating agent ratios (POL:AA) of 5:1, 5:2 and 5:3, respectively (Table 1 ). Then, suspensions were mechanically mixed and sonicated (Wisd, Ultrasonic Cleaner, Model\#: WUC-A03H, $40 \mathrm{kHz}$ ) for $3 \mathrm{~h}$ at room temperature and following that, samples were dried in convection oven (Kenton China, KH-35A) at $100{ }^{\circ} \mathrm{C}$ for $12 \mathrm{~h}$.

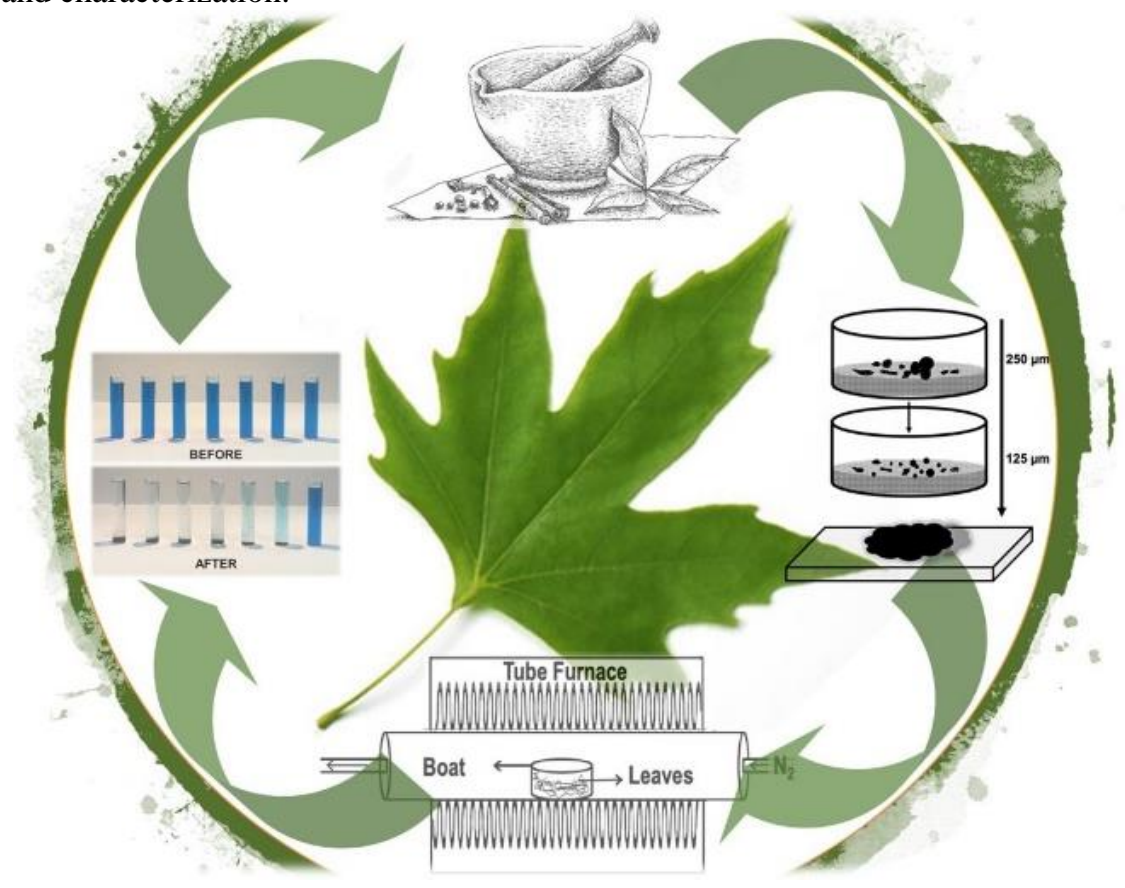

Figure 1. Schematic illustration of experimental procedure

All dried samples were carbonized at $700{ }^{\circ} \mathrm{C}$ for $1 \mathrm{~h}$ with $5{ }^{\circ} \mathrm{C} \mathrm{min}{ }^{-1}$ heating rate under $\mathrm{N}_{2}$ flow of $1 \mathrm{~L} \mathrm{~min}^{-1}$ in the tube furnace (MTI, OTF-1200F). The carbonization yield was calculated according to following equation:

$$
\% \text { Yield }=\text { Mass }_{\text {output }} / \text { Mass }_{\text {input }} \times 100
$$

The carbonized leaves were treated with $1 \mathrm{M} \mathrm{HCl}$ solution to remove $\mathrm{Zn}$ metal or $\mathrm{ZnO}$. Then, samples were purified with deionized water and ethanol until getting neutral $\mathrm{pH}$, and samples further dried at $80{ }^{\circ} \mathrm{C}$ for $24 \mathrm{~h}$. For comparison, ground and sieved leaves were directly carbonized without any extra treatment. Sample code, content, carbonization yield and weight loss values were given in Table 1 .

\section{Structural, Morphological and Textural Characterization}

The surface morphology of the samples was analyzed by a field emission scanning electron microscope (FESEM, $30 \mathrm{kV}$ ). Prior to analysis samples were sputter coated $(3-6 \mathrm{~nm})$ by $\mathrm{Au} / \mathrm{Pd}$ alloy. Structural 
properties of the samples were characterized by using Fourier transform infrared spectroscopy (FTIR, Perkin Elmer, Spectrum 100 IR) and attenuated total internal reflectance (ATR) spectroscopy was used. Spectra were recorded between 550 and $4000 \mathrm{~cm}^{-1}$ in the transmittance mode with spectral resolution of $4 \mathrm{~cm}^{-1}$ at a scan rate of 4 scans. Surface texture of activated carbon was characterized by $\mathrm{N}_{2}$ adsorption at $77 \mathrm{~K}$ using a surface area analyzer (Quantachrome Co., USA). All samples were degassed at $120^{\circ} \mathrm{C}$ for $3 \mathrm{~h}$.

Table 1. Sample identification and production yield values of activated carbon

\begin{tabular}{ccc|c}
\hline $\begin{array}{c}\text { Sample } \\
\text { Code }\end{array}$ & Leaf content $(\mathbf{g})$ & $\begin{array}{c}\mathbf{Z n C l}_{2} \text { content } \\
(\mathbf{g})\end{array}$ & \% Yield \\
\hline S1 & 5.00 & 0.00 & 28.45 \\
S2 & 5.00 & 1.00 & 34.49 \\
S3 & 5.00 & 2.00 & 39.36 \\
S4 & 5.00 & 3.00 & 41.57 \\
\hline
\end{tabular}

\section{Analysis of Methylene Blue Adsorption}

The concentration of MB (Merck) in solution was determined by using a UV-visible spectrophotometer (PG Instruments) at $\lambda_{\max }: 668 \mathrm{~nm}$. Adsorption isotherms were determined by using different initial MB concentrations $\left(0.5-20 \mathrm{mg} \mathrm{L}^{-1}\right)$ around $\sim \mathrm{pH} 5.5$. Equal masses of $0.01 \mathrm{~g}$ of adsorbent were added to 100 $\mathrm{mL}$ solutions. Samples were agitated for $24 \mathrm{~h}$ at $25^{\circ} \mathrm{C}$. The samples were centrifuged at $3000 \mathrm{rpm}$ for $10 \mathrm{~min}$ prior to measurements. The amounts of adsorbed MB at equilibrium $\left(Q_{\mathrm{e}}, \mathrm{mg} \mathrm{g}^{-1}\right)$ and at time $\left(Q_{\mathrm{t}}, \mathrm{mg} \mathrm{g}^{-1}\right)$ were calculated by using following equations:

$$
\begin{aligned}
& Q_{e}=\left(C_{0}-C_{E}\right) \times V / m \\
& Q_{t}=\left(C_{0}-C_{t}\right) \times V / m
\end{aligned}
$$

where $\mathrm{C}_{0}, \mathrm{C}_{\mathrm{E}}$ and $\mathrm{C}_{\mathrm{t}}\left(\mathrm{mg} \mathrm{L}^{-1}\right)$ are the concentrations of $\mathrm{MB}$ at start, at equilibrium and at time $\mathrm{t}(5-120 \mathrm{~min})$, respectively. $\mathrm{m}(\mathrm{g})$ is the mass of adsorbent and $\mathrm{V}(\mathrm{L})$ is the volume of the solution.

\section{Results and Discussion Morphological Characterization}

In order to understand the effect of activator to biomass ratio on surface morphology, FESEM was used. SEM images of $\mathrm{S} 1$ - S4 were shown in Fig. 2. Low magnification and high magnification of the samples were given in order to see the particle and surface morphology. All samples showed similar particle morphology regardless of the content. However, surface morphology showed some differences. Parallel with the BET analysis S3 showed more features on the surface those probably led to higher methylene blue absorption.

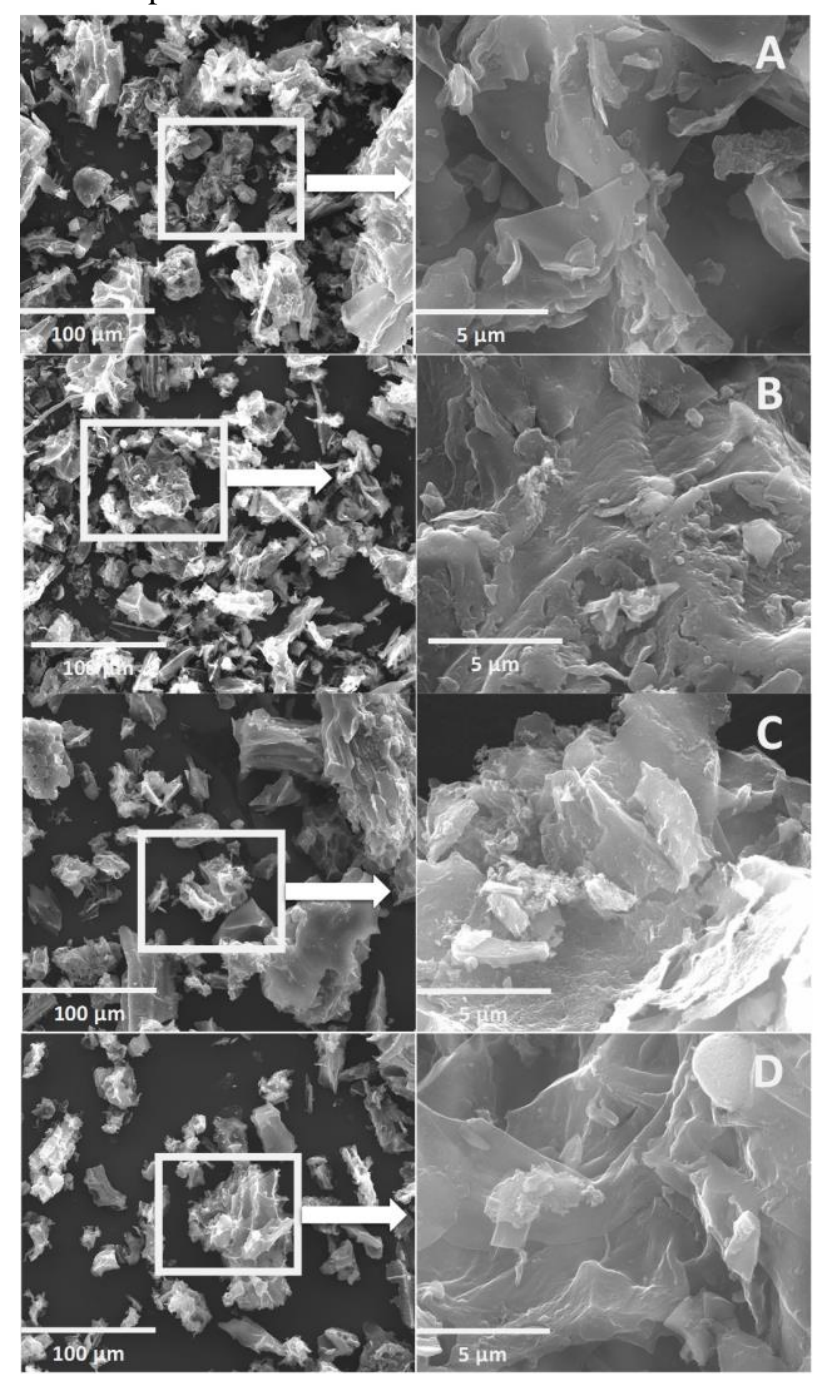

Figure 2. SEM images of carbonized and activated POL samples at different magnifications: a) S1, b) S2, c) S3 and d) S4 


\section{BET Isotherms}

The isotherms of $\mathrm{S} 2, \mathrm{~S} 3$ and $\mathrm{S} 4$ seemed to be combination of Type I and Type II of the IUPAC classification which observed with solids of plate-like particles that create slit-shaped pores (Sing et al., 1985).
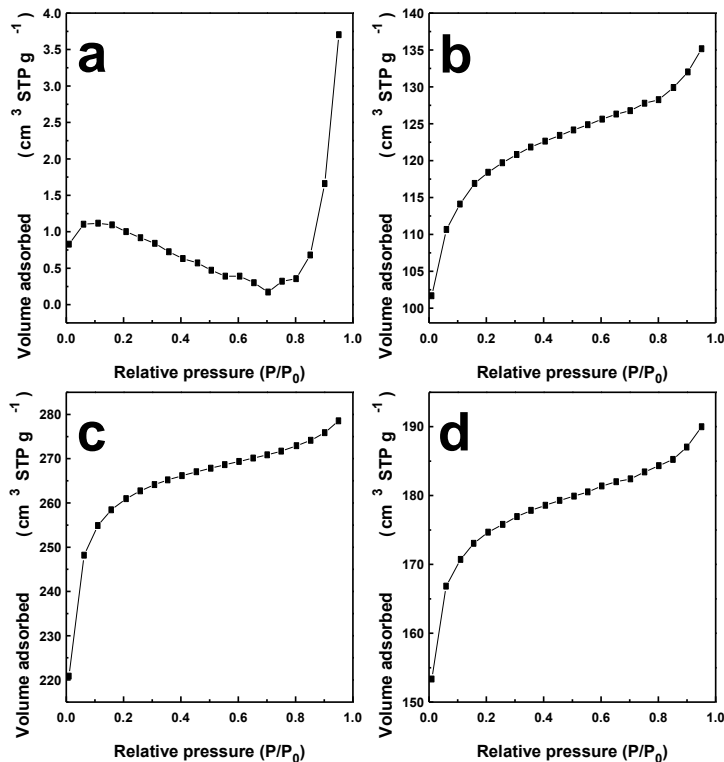

Figure 3. Adsorption isotherms of $\mathrm{N}_{2}$ at STP for a) S1, b) $\mathrm{S} 2$, c) $\mathrm{S} 3$ and d) $\mathrm{S} 4$

All textural parameters related with samples were summarized in Table 2. As seen from the results, surface area of activated carbon samples was increased from 90 to 200 times by thermochemical activation. According to average pore radius results, mesoporous structure of carbonized platanus orientalis leaves was turned into microporous structure by activation. Also, around four times increment was observed in pore volume of the carbonized leaves by activation.

Table 2. Textural parameters of inactivated and activated carbon from platanus orientalis leaves

\begin{tabular}{ccccc}
\hline $\begin{array}{c}\text { Sample } \\
\text { No }\end{array}$ & $\begin{array}{c}\text { Surface } \\
\text { Area } \\
\left(\mathbf{m}^{\mathbf{2}} \mathbf{g}^{-1}\right)\end{array}$ & $\begin{array}{c}\text { Average } \\
\text { Pore } \\
\text { Radius } \\
(\mathbf{n m})\end{array}$ & $\begin{array}{c}\text { Pore } \\
\text { Volume } \\
\left(\mathbf{c m}^{\mathbf{3}} \mathbf{g}^{-\mathbf{1}}\right)\end{array}$ & $\begin{array}{c}\text { Total Pore } \\
\text { Volume } \\
\left(\mathbf{c m}^{\mathbf{3}} \mathbf{g}^{-\mathbf{1}}\right)\end{array}$ \\
\hline S1 & 4.740 & 2.41680 & 0.007 & 0.005728 \\
S2 & 454.795 & 0.91940 & 0.028 & 0.2091 \\
S3 & 1023.92 & 0.84161 & 0.029 & 0.4309 \\
S4 & 687.074 & 0.85542 & 0.026 & 0.2939 \\
\hline
\end{tabular}

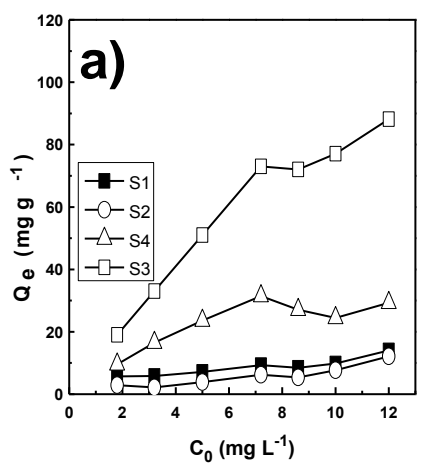

\section{FTIR Spectroscopy}

As shown in Fig. 4, FTIR measurements were performed for all inactivated (S1) and activated carbon samples. All activated carbon samples showed identical patterns. There exhibited a broad absorption band at $3200-3500 \mathrm{~cm}^{-1}$, which corresponds to the stretching vibration of -OH group in all samples (ElShafei, ElSherbiny, Darwish, and Philip, 2017). There were two characteristic peaks appeared at 2920 and $2850 \mathrm{~cm}^{-1}$ corresponding to $\mathrm{sp}^{3}-\mathrm{CH}$ stretching (Bhadusha and Ananthabaskaran, 2011). Also, additional aromatic $\mathrm{C}=\mathrm{C}$ stretching peak at $1660 \mathrm{~cm}^{-1}$ was observed for all samples (Fanning and Vannice, 1993; Mopoung, Moonsri, Palas, and Khumpai, 2015). It was also observed broad aromatic $\mathrm{sp}^{2}-\mathrm{CH}$ bend at $800-950 \mathrm{~cm}^{-1}$ for activated carbon samples (Guo and Lua, 2002). The characteristic transmission \% intensity was gradually increased with the increase of $\mathrm{ZnCl}_{2}$ addition during carbonization.

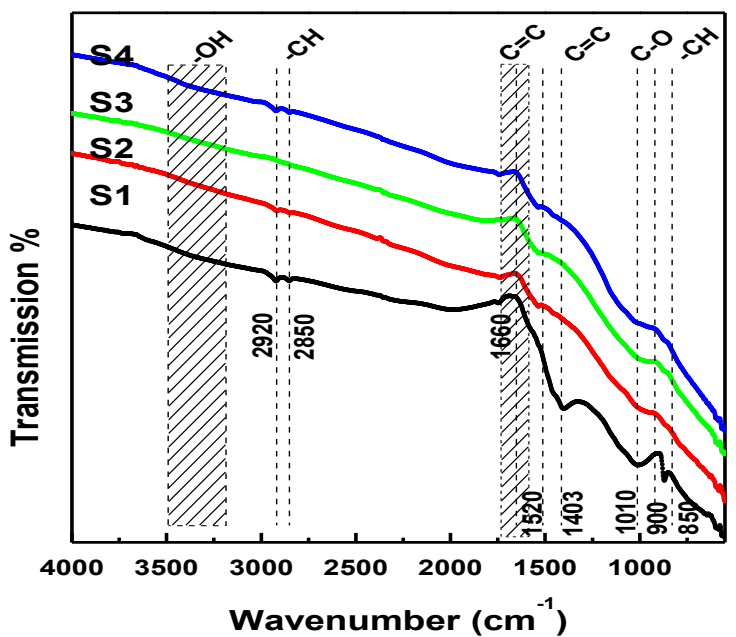

Figure 4. FTIR spectra of carbonized (S1) and activated (S2, S3, S4) platanus orientalis leaves

\section{Adsorption isotherms}

The effect of carbon source on MB adsorption at 12 ppm initial dye concentration is shown in Fig. 5b. It is obvious that the percentage of dye removal of $\mathrm{S} 3$ is the highest value $(73.45 \%)$. The dye removal efficiencies of S1, S2 and S4 are $23.36 \%, 20.18 \%$ and $48.84 \%$, respectively.

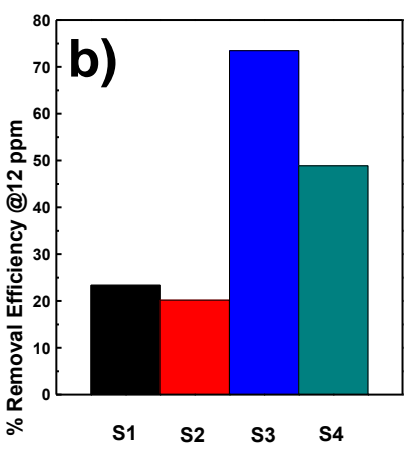

Figure 5. a) MB removal by using different carbon sources and different initial MB concentrations, b) MB removal efficiencies of different carbon sources at $12 \mathrm{ppm} \mathrm{MB}$ concentration 
The characteristics of Langmuir isotherm can be expressed by using separation factor $\left(R_{L}\right)$ which is defined by:

$$
R_{L}=\frac{1}{1+k_{l} C_{0}}
$$

where $\mathrm{k}_{1}$ and $\mathrm{C}_{0}$ are Langmuir constant and the highest dye concentration, respectively. According to adsorption isotherm shown in Fig. 6a, $\mathrm{R}_{\mathrm{L}}$ value was found as 0.074 which indicates type of the isotherm to be favorable (Kadirvelu, Thamaraiselvi, and Namasivayam, 2001).
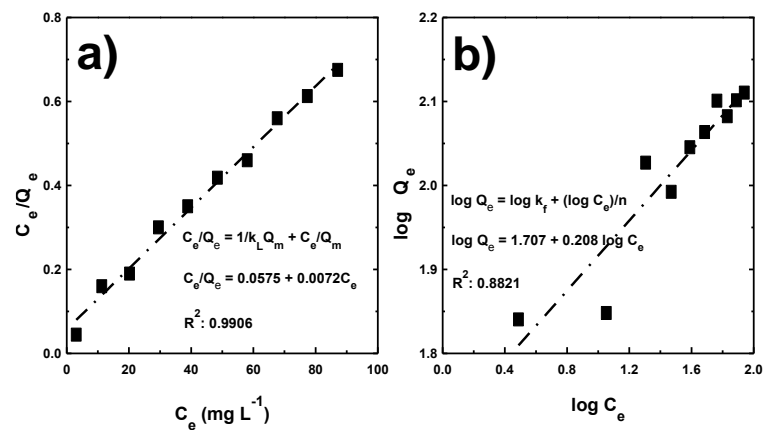

Figure 6. a) Langmuir and b) Freundlich adsorption isotherms of $\mathrm{MB}$ dye onto $\mathrm{S} 3$

Table 3. Adsorption isotherms and their constants for MB adsorption on S3

\begin{tabular}{lclc}
\multicolumn{1}{c}{ Model } & Equation & Constants & Values \\
\hline \multirow{2}{*}{$\begin{array}{c}\text { Langmuir } \\
\text { isotherm }\end{array}$} & $C_{e} / Q_{e}$ & $\mathrm{k}_{\mathrm{l}}$ & 0.1252 \\
& $=C_{e} / Q_{\max }$ & $\mathrm{Q}_{\max }$ & 138.888 \\
& $+1 / k_{l} Q_{\max }$ & $\mathrm{R}_{\mathrm{L}}$ & 0.9906 \\
\hline \multirow{2}{*}{ Freundlich } & $\log Q_{e}$ & $\mathrm{k}_{\mathrm{f}}$ & 0.074 \\
isotherm & $=\log k_{f}-\left(\log C_{e}\right) / n$ & $\mathrm{~N}$ & 50.933 \\
& & $\mathrm{R}^{2}$ & 0.7892 \\
\hline
\end{tabular}

\section{Adsorption kinetics}

In this study, adsorption kinetics of MB on S3 were analyzed by using 3 different kinetic models (Fig. 7). The rate of removal $\%$ of dye molecules from solution and time dependent dye concentration by using S3 were seen in the Fig. 7a. All the MB molecules were removed from solution in $5 \mathrm{~h}$ and corresponding equivalent concentration of MB was found $41.0298 \mathrm{mg}$ $\mathrm{g}^{-1}$. The most effective model was determined according to consistency between theoretical and experimental results $\left(\mathrm{R}^{2}\right.$ values). All kinetic model equations and corresponding model parameters were given in Table 4. In the first model (LagergrenSvenska model), it is assumed that adsorption rate is proportional to the difference between equivalent $\left(\mathrm{Q}_{\mathrm{e}}\right)$ and time dependent concentration $\left(\mathrm{Q}_{\mathrm{t}}\right)$ (Rudzinski and Plazinski, 2006). As seen from Fig. 7b, there was a linear relationship between $\log \left(\mathrm{Q}_{\mathrm{e}}-\mathrm{Q}_{\mathrm{t}}\right)$ and time. $\mathrm{k}_{1}$ and $\mathrm{Q}_{\mathrm{e}}$ values were calculated from the slope and intercept of the plot, respectively (Table 4). Like pseudo firstorder kinetic model, the linear relationship between $t / Q_{t}$ and time was observed for pseudo-second-order kinetic model. $\mathrm{Q}_{\mathrm{e}}$ and $\mathrm{k}_{2}$ values were calculated from the slope and intercept of the plot, respectively (Table 4).
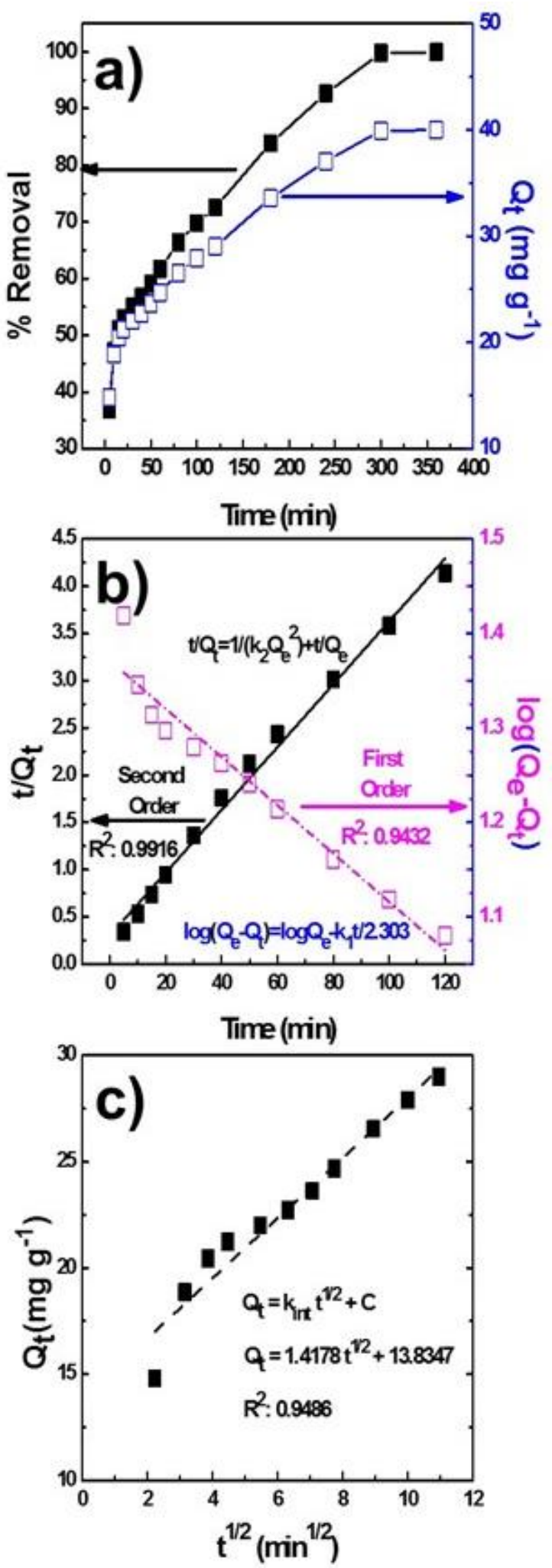

Figure 7. a) Time dependency of MB removal/adsorption by using $\mathrm{S} 3$, b) corresponding pseudo-first and -second order model plots, and c) Weber-Morris intra-particle diffusion model

In addition to first- and second-order models, diffusion mechanism of MB was analyzed by using intra-particle diffusion model (Fig. 7c). According to this model, 
adsorption of dye molecules on adsorbent occurs in two steps. Dye molecules firstly migrate from solution to the surface of adsorbent and then diffuse into interior pores of adsorbent (Doke and Khan, 2017). There was a linear relationship between $Q_{t}$ and $t^{1 / 2} \cdot k_{\text {int }}$ and $\mathrm{C}$ values were calculated from the slope and intercept of the plot, respectively (Table 4). As seen from Fig. 7c, fitted line was not passing through the origin. This indicates that adsorption process has not only been controlled by intra-particle diffusion. Among these models, pseudo-second order kinetic model gave the highest $\mathrm{R}^{2}$ value which was 0.9916 . So, pseudosecond-order model was the best model to explain MB adsorption process onto $\mathrm{S} 3$.

Table 4. Kinetic model parameters of MB adsorption on $\mathrm{S} 3$

\begin{tabular}{lllc}
\multicolumn{1}{c}{ Model } & \multicolumn{1}{c}{ Equation } & Constants & Values \\
\hline $\begin{array}{l}\text { Lagergren- } \\
\text { Svenska }\end{array}$ & $\log \left(Q_{e}-Q_{t}\right)$ & $\mathrm{k}_{1}$ & $5.9878^{*} 10^{-}$ \\
model & $=\log Q_{e}$ & & 3 \\
& $-k_{1} t / 2.303$ & $\mathrm{Q}_{\mathrm{e}}$ & 23.5179 \\
& $\mathrm{R}^{2}$ & 0.9432 \\
Pseudo & ${ }^{t} / Q_{t}$ & $\mathrm{k}_{2}$ & 0.00368 \\
second- & $=1 / k_{2} Q_{e}{ }^{2}$ & $\mathrm{Q}_{\mathrm{e}}$ & 30.03003 \\
order model & $+{ }^{2} / Q_{e}$ & & 0.9916 \\
& & $\mathrm{R}_{\mathrm{int}}$ & \\
\hline $\begin{array}{l}\text { Intra- } \\
\text { particle }\end{array}$ & $Q_{t}$ & $\mathrm{C}$ & 1.4178 \\
diffusion & $=k_{\text {int }} t^{1 / 2}+C$ & $\mathrm{R}^{2}$ & 0.9486 \\
model & & & \\
\hline
\end{tabular}

It was known that activated carbon production from lignocellulosic materials strongly depends on activation method. For future studies, it is recommended to use different activation chemicals, different activation and carbonization conditions to improve surface texture or adsorption characteristics. Also, stability, scalability, and recycling of adsorbent under different conditions should be studied for a sustainable filtration process afterwards. In addition to adsorption or filtration applications, this material might be a good alternative for energy storage and conversion applications such as electrode materials for capacitors or secondary batteries or can be used as additives for separators. Future research will be focused on these applications.

\section{Conclusions}

The present study showed that platanus orientalis leaves can be used as an alternative raw material for activated carbon production for the removal of MB dye from aqueous media. Surface area of POL was increased around 200 times by the thermochemical activation $\left(\sim 1024 \mathrm{~m}^{2} \mathrm{~g}^{-1}\right)$. Adsorption behavior of activated POL is described by a monolayer Langmuir type isotherm. Kinetic data of activated POL follow second order kinetic model. The value of the maximum adsorption capacity, $\mathrm{Q}_{\mathrm{e}}\left(30.03 \mathrm{mg} \mathrm{g}^{-1}\right)$ is better than commercial activated carbon reported in earlier studies. Since POLs have high cellulosic content and micropores on their surfaces, they might be promising materials for active carbon fabrication.

\section{Acknowledgements}

The authors wish to express their sincere thanks to Assoc. Prof. Dr. Ugur Cengiz for FTIR and BET measurements.

\section{References}

Abadian, S., Rahbar-Kelishami, A., Norouzbeigi, R., and Peydayesh, M. (2015). Cu(II) adsorption onto Platanus orientalis leaf powder: kinetic, isotherm, and thermodynamic studies. Research on Chemical Intermediates, 41(10), 7669-7681. doi:10.1007/s11164-014-1851-y

Bhadusha, N., Ananthabaskaran, T. (2011). Adsorptive Removal of Methylene Blue onto $\mathrm{ZnCl}<$ sub $>2</$ sub $>$ Activated Carbon from Wood Apple Outer Shell: Kinetics and Equilibrium Studies. E-Journal of Chemistry, 8, 429831. doi:10.1155/2011/429831

Dahiya, D., Nigam, P. S. (2020). Waste Management by Biological Approach Employing Natural Substrates and Microbial Agents for the Remediation of Dyes' Wastewater. Applied Sciences, 10(8). doi:10.3390/app10082958

Doke, K. M., Khan, E. M. (2017). Equilibrium, kinetic and diffusion mechanism of $\mathrm{Cr}(\mathrm{VI})$ adsorption onto activated carbon derived from wood apple shell. Arabian Journal of Chemistry, 10, S252S260, doi.org/10.1016/j.arabjc. 2012.07.031

Dotto, G. L., Santos, J. M. N., Rodrigues, I. L., Rosa, R., Pavan, F. A., Lima, E. C. (2015). Adsorption of Methylene Blue by ultrasonic surface modified chitin. Journal of colloid and interface science, 446, 133-140, doi.org/ 10.1016/j.jcis.2015.01.046

ElShafei, G. M. S., ElSherbiny, I. M. A., Darwish, A. S., Philip, C. A. (2017). Artichoke as a nonconventional precursor for activated carbon: Role of the activation process. Journal of Taibah University for Science, 11(5), 677-688. doi:10.1016/j.jtusci.2016.04.006

Fanning, P. E., Vannice, M. A. (1993). A DRIFTS study of the formation of surface groups on carbon by oxidation. Carbon, 31(5), 721-730. doi.org/10.1016/0008-6223(93)90009-Y

Gu, L., Wu, S., Li, B., Wen, H., Zhang, D., Ye, J., Wang, L. (2017). Persulfate oxidation assisted hydrochar production from Platanus Orientalis Leaves: Physiochemical and combustion characteristics. Bioresource Technology, 244, 517-524. doi.org/10.1016/j.biortech.2017.07.173

Guo, J., Lua, A. C. (2002). Characterization of adsorbent prepared from oil-palm shell by $\mathrm{CO} 2$ activation for removal of gaseous pollutants. Materials Letters, 55(5), 334-339. doi.org/10.1016/S0167-577X(02)00388-9

Jiang, X., Sun, P., Xu, L., Xue, Y., Zhang, H., Zhu, W. (2020). Platanus orientalis leaves based hierarchical porous carbon microspheres as high efficiency adsorbents for organic dyes removal. Chinese Journal of Chemical Engineering, 28(1), 254-265. doi.org/10.1016/j.cjche.2019.03.030 
Kadirvelu, K., Thamaraiselvi, K., Namasivayam, C. (2001). Adsorption of nickel(II) from aqueous solution onto activated carbon prepared from coirpith. Separation and Purification Technology, 24(3), 497-505. doi.org/10.1016/S13835866(01)00149-6

Kuang, Y., Zhang, X., Zhou, S. (2020). Adsorption of Methylene Blue in Water onto Activated Carbon by Surfactant Modification. Water, 12(2). doi: 10.3390/w12020587

Liu, X., Huang, L., Wang, L., Wang, C., Wu, X., Dong, G., Liu, Y. (2018). Preparation, adsorptive properties and chemical regeneration studies of high-porous activated carbon derived from Platanus orientalis leaves for $\mathrm{Cr}(\mathrm{VI})$ removal. Journal of Water and Health, 16(5), 814-826. doi:10.2166/wh.2018.068

Macedo, J. d. S., da Costa Júnior, N. B., Almeida, L. E., Vieira, E. F. d. S., Cestari, A. R., Gimenez, I. d. F., Barreto, L. S. (2006). Kinetic and calorimetric study of the adsorption of dyes on mesoporous activated carbon prepared from coconut coir dust. Journal of colloid and interface science, 298(2), 515-522, doi.org/10. 1016/j.jcis.2006.01.021

Mahvi, A. H., Nouri, J., G.A.Omrani, Gholami, F. (2007). Application of Platanus Orientalis Leaves in Removal of Cadmium from Aqueous Solution. World Applied Sciences Journal, 2(1), 40-44.

Mopoung, S., Moonsri, P., Palas, W., Khumpai, S. (2015). Characterization and Properties of Activated Carbon Prepared from Tamarind Seeds by $\mathrm{KOH}$ Activation for $\mathrm{Fe}(\mathrm{III})$ Adsorption from Aqueous Solution. The Scientific World Journal, 2015, 415961. doi:10.1155/2015/415961

Musah, B. I., Peng, L., Xu, Y. (2020). Adsorption of Methylene Blue Using Chemically Enhanced Platanus orientalis Leaf Powder: Kinetics and Mechanisms. Nature Environment Pollution Technology, 19(1), 29-40.

Norouzi, S., Khademi, H. (2015). Source identification of heavy metals in atmospheric dust using Platanus orientalis L. leaves as bioindicator. Eurasian Journal of Soil Science, 4(3), 144-152. doi.org/10.18393/ejss.2015.3.144-152

Peydayesh, M., and Rahbar-Kelishami, A. (2015). Adsorption of methylene blue onto Platanus orientalis leaf powder: Kinetic, equilibrium and thermodynamic studies. Journal of Industrial and Engineering Chemistry, 21, 1014-1019. doi.org/10.1016/j.jiec.2014.05.010

Rinaldi, R., Cafasso, D., Strumia, S., Cristaudo, A., Sebastiani, F., Fineschi, S. (2019). The influence of a relict distribution on genetic structure and variation in the Mediterranean tree, Platanus orientalis. AoB PLANTS, 11(1). doi:10. 1093/aobpla/plz002

Rudzinski, W., Plazinski, W. (2006). Kinetics of Solute Adsorption at Solid/Solution Interfaces: A Theoretical Development of the Empirical Pseudo-First and Pseudo-Second Order Kinetic Rate Equations, Based on Applying the Statistical Rate Theory of Interfacial Transport. The Journal of Physical Chemistry B, 110(33), 16514-16525. doi:10.1021/jp061779n

Sert, Ş., Kütahyali, C., İnan, S., Talip, Z., Çetinkaya, B., Eral, M. (2008). Biosorption of lanthanum and cerium from aqueous solutions by Platanus orientalis leaf powder. Hydrometallurgy, 90(1), 13-18. doi.org/10.1016/j.hydromet.2007.09.006

Sevik, H., Cetin, M., Ozturk, A., Yigit, N., Karakus, O. (2019). Changes in micromorphological characters of Platanus orientalis L. leaves in Turkey. J Applied Ecology Environmental Research, 17(3), 5909-5921.

Sing, K. S. W., Everett, D. H., Haul, R. A. W., Moscou, L., Pierotti, R. A., Rouquerol, J., Siemieniewska, T. (1985). Reporting Physisorption Data for Gas/Solid System with Special Reference to the Determination of Surface Area and Porosity. Pure and Applied Chemistry, 57(4), 603-619, dx.doi.org/10.1351/ pac198557040603

Tan, I. A. W., Ahmad, A. L., Hameed, B. H. (2008). Adsorption of basic dye on high-surface-area activated carbon prepared from coconut husk: Equilibrium, kinetic and thermodynamic studies. Journal of Hazardous Materials, 154(1), 337346. doi.org/10.1016/j.jhazmat.2007.10.031

Wong, Y. C., Szeto, Y. S., Cheung, W. H., McKay, G. (2004). Adsorption of acid dyes on chitosan equilibrium isotherm analyses. Process Biochemistry, 39(6), 695-704, doi.org/10.1016/ S0032-9592(03)00152-3 